\title{
Cooperativismo y Universidad: pasado y presente
}

\author{
Dante Cracogna
}

Sumario: 1. Los inicios.-2. Los primeros contactos.-3. Nuevas etapas.-4. Investigación y docencia.-5. Posibles soluciones. -6. Conclusión.

\section{Los inicios}

Cuando surge el cooperativismo en su concepción actual durante el apogeo de la Revolución Industrial en Inglaterra con las cooperativas de consumo y en forma más o menos simultánea en Francia con las cooperativas de trabajo y en Alemania con las cooperativas de crédito y de comercialización agraria, la universidad ya era una institución varias veces centenaria. Sin embargo, huelga decir que ninguna relación existió entre ambos. En rigor, nada más alejado del ambiente y de las inquietudes académicas que una experiencia económica y social surgida - como afirmó Charles Gide- «de las entrañas mismas del pueblo». No es de extrañar, pues, que uno y otra se mantuvieran alejados entre sí durante mucho tiempo y que, aun hoy, sólo en pocos casos tengan alguna relación que vaya más allá de lo circunstancial.

Es que las cooperativas, nacidas de las necesidades de la gente común (trabajadores, agricultores, artesanos) se constituyeron según el patrón de sus propias circunstancias de lugar y tiempo, adecuándose a los peculiares requerimientos de su subsistencia y desarrollo sin tener en cuenta postulados de doctrina alguna ni de teoría o pensamiento determinados. Ello así aun en los casos en los que las cooperativas fueron inicialmente promovidas por personas que tenían ideas sociales definidas, como W. Raiffeisen, H. Shultze-Delistch, L. Bouchez o L. Blanc.

A lo sumo, las distintas cooperativas tenían en común ciertos ideales de mejoramiento individual y colectivo y algunos principios para tratar de lograrlos, tales como el esfuerzo propio, la ayuda mutua y la organización asociativa. Pero no existía un cuerpo orgánico de teoría que 
les diera sustento ni se asentaban sobre las ideas de un pensador determinado, aun cuando tuvieran influencia de alguno, como ocurría con R. Owen en las cooperativas inglesas. Resulta comprensible, entonces, que no llegara a la universidad el interés por estas manifestaciones de la vida social caracterizadas por su difusión entre sectores de menor significación económica y social que procuraban resolver problemas de grupos reducidos y, en general, sin pretensión de trascendencia al conjunto de sociedad.

En el campo de lo que hoy llamamos «ciencias sociales» la universidad ha solido ocuparse del análisis de los movimientos que alcanzan a sectores importantes de la población o que involucran significativas cantidades de recursos o bien al estudio de las teorías o doctrinas - generalmente elaboradas por sus propios integrantes - que tienen la pretensión de erigirse en sistemas que explican la organización social, económica o política o que la cuestionan y postulan su transformación. De manera que no resulta extraño que el quehacer de la universidad y del cooperativismo discurrieran por carriles diferentes, sin contacto entre sí.

\section{Los primeros contactos}

La situación descripta comenzó a encontrar algún cambio cuando sucedieron dos hechos, que a veces estuvieron vinculados entre sí pero no necesariamente. Uno de ellos tuvo lugar cuando algunas experiencias cooperativas fueron alcanzando cierto grado de desarrollo como para comenzar a ser advertidas por estudiosos que, consiguientemente, las tomaron en cuenta en su actividad académica. El otro sucedió cuando algunos miembros de la universidad dotados de una especial sensibilidad social se comprometieron personalmente en la actividad cooperativa y, al hacerlo, aportaron simultáneamente nuevos elementos de análisis para su propio quehacer académico. Lo sucedido en Inglaterra con A. Marshall es representativo de la nueva situación, al igual que el destacado caso de Charles Gide en Francia. Sin embargo, éstos no fueron los únicos casos entre los economistas ya que L. Walras y $\mathrm{W}$. Pareto constituyen otros ejemplos relevantes al igual que $\mathrm{O}$. Gierke en el campo jurídico en Alemania, entre otros.

Lo cierto es que, especialmente a partir de fines del siglo XIX y comienzos del siglo pasado, comienza una nueva etapa de la relación entre la universidad y el cooperativismo caracterizada por el interés particular de algunos profesores acerca de las cooperativas lo cual contribuyó, obviamente, a potenciar un sidesarrollo teórico del cual el coo- 
perativismo había carecido hasta ese momento. Si bien se trataba de casos aislados y dispersos, la contribución de estos académicos fue configurando la base de una verdadera teoría de la cooperación. Y a medida que esos aportes iban siendo mutuamente conocidos por sus respectivos autores fue creciendo significativamente el nivel de su interés y tejiéndose paulatinamente una red de enriquecimiento y progreso común.

\section{Nuevas etapas}

La siguiente etapa habría de ser el paso, a veces no programado ni aun deliberadamente adoptado, de los esfuerzos teóricos individuales de determinados miembros de la universidad a la incorporación del estudio del cooperativismo de manera relativamente orgánica y sistemática dentro de la labor académica en forma regular. Un precedente destacado fue el del Ruskin College de Oxford que dictó cursos por correspondencia ya al comienzo del Siglo Xx. Promediando el siglo eran varias las universidades europeas y de las Américas que contaban con cátedras de la materia y aun con unidades académicas especializadas.

Este nuevo estadio implicó que la universidad viniera a ocuparse tanto del estudio acerca del cooperativismo —como hasta entonces había sucedido- como también de la docencia o enseñanza de la materia, actividad inédita en el ámbito universitario. En efecto, por vez primera la universidad se ocupa de la enseñanza del cooperativismo junto con la de otras disciplinas y se produce una integración de diversas asignaturas en torno y a propósito de ella puesto que comienza a estudiarse y enseñarse la economía, la administración y el derecho de las cooperativas.

Especialmente en las décadas de los '60 y '70, algunas universidades cumplieron una importante tarea de promoción de las cooperativas y de apoyo a la creación de centros universitarios de cooperativismo en países en vías de desarrollo. Ejemplos de esa labor fueron los institutos de cooperativismo de las universidades alemanas de Münster en los países de América Latina y de Marburgo en Asia y Africa. También se realizaron interesantes tareas de formación de recursos humanos del Tercer Mundo en los centros universitarios de Sherbrooke, Canadá, y Wisconsin, EEUU. De esa forma, la actividad de las universidades se proyectó internacionalmente contribuyendo —con variado éxito- a ampliar el horizonte de sus propios profesores a la vez que promovían experiencias similares en otros países. 


\section{Investigación y docencia}

En algunos casos la investigación y la docencia sobre el cooperativismo discurren por canales diferentes. Cuando esto sucede, la investigación corre ciertamente el riesgo de alejarse de la realidad y convertirse en una suerte de entretenimiento intelectual inconducente. Por otro lado, la docencia se convierte en una mera repetición sin hondura ni originalidad cuando no se halla apuntalada por la investigación. Este es el problema con el que frecuentemente se enfrentaron las universidades que acogieron el cooperativismo como parte de su quehacer académico. Y no son pocas las que aun no lo han resuelto, especialmente en el caso de las que cuentan solamente con actividad de enseñanza, las que suelen convertirse en meras dispensadoras de cursos, máxime cuando los realizan como parte de una actividad de «extensión» y sin el rigor propio de los estudios universitarios.

Es verdad que a veces las propias cooperativas o sus organizaciones de integración acuden a la universidad para promover que ésta se ocupe del cooperativismo y aun aportan recursos para la creación de institutos especializados en la enseñanza. Todo ello con la bienintencionada expectativa de que la universidad ayude a formar cuadros ejecutivos y dirigenciales que sean idóneos para llevar adelante la actividad de las cooperativas. Esa esperanza se funda en la creencia de que por el sólo hecho de tratarse de la universidad se halla garantizada una formación adecuada de los recursos humanos, sin tener en consideración si la universidad cuenta a su vez con los recursos humanos propios adecuadamente preparados para realizar esa labor; especialmente, si dispone de los investigadores que brinden los fundamentos específicos para la actividad docente y no solamente si cuenta con personal para impartir clases. La falta de atención a este aspecto ha llevado a no pocas desilusiones, tanto para las organizaciones cooperativas que no obtienen los resultados esperados como para las propias universidades que se revelan incapaces de producirlos. Ello conduce a mutua desconfianza y decepción; y los intentos del movimiento cooperativo de crear sus propias universidades como forma de asegurar que ellas respondan cabalmente a su orientación y necesidades no han demostrado aun que sean capaces de resolver el problema.

Una adicional situación que suele presentarse como corolario de la actividad docente de algunas universidades consiste en la producción de sucesivas camadas de egresados portadores de títulos académicos relacionados con el cooperativismo que, con lógica expectativa, acuden a la búsqueda de posiciones laborales que estiman acordes con su formación. Y con cierta frecuencia ocurre que - por diversas razones- 
no encuentran dichas posiciones generándose la consiguiente frustración y malgasto de esfuerzos personales e institucionales.

En general, estos casos suelen producirse como consecuencia de la falta de ajuste entre las necesidades profesionales y laborales de las cooperativas y «el producto» que la universidad ofrece o bien por cuanto, a veces, las cooperativas recelan de tales egresados y prefieren los que exhiben títulos que se hallan acreditados como idóneos para el mercado empresario en general. Empero, en este último caso, los portadores de esos títulos suelen no tener siquiera información acerca de las cooperativas y sus características puesto que a lo largo de sus respectivas carreras solamente se han familiarizado con otras formas de organización empresarial y, fundamentalmente, con las sociedades de capital. Empero, el prestigio de tales carreras suele encandilar a quienes están encargados de reclutar los recursos humanos de las cooperativas.

\section{Posibles soluciones}

Lo antedicho lleva a pensar si no sería más fructífero, en lugar de desarrollar carreras específicamente vinculadas con el cooperativismo como se ha hecho en muchos casos, tratar de penetrar las careras tradicionales con algunos contenidos acerca del cooperativismo. Tal podría realizarse, obviamente, en las carreras de administración, de economía, de derecho, de contabilidad y otras. De esa suerte, los egresados de ellas - aun no siendo especialistas en cooperativismo- contarían al menos con ciertos conocimientos básicos sobre la materia que los habiliten, juntamente con su formación profesional general, para cumplir con idoneidad sus funciones en las cooperativas. Las unidades académicas dedicadas a los estudios cooperativos en la universidad, en lugar de dictar carreras especializadas, podrían fungir como proveedoras de los docentes encargados de dictar los cursos específicos dentro de los programas de estudio de las diferentes carreras.

Una tendencia que se viene acrecentando en época reciente consiste en el establecimiento de vínculos más o menos regulares y permanentes entre los centros o institutos de cooperativismo de las distintas universidades. Dichos vínculos llegan incluso a la formación de redes, especialmente en materia de investigación en la que suelen llevarse a cabo proyectos conjuntos con la participación de varios de ellos. Muestras de esta nueva tendencia se encuentran entre universidades de Europa y de las Américas, las cuales contribuyen a potenciar el trabajo de los centros abriendo nuevas perspectivas y logrando un mejor aprovechamiento de los recursos humanos y materiales disponibles. 


\section{Conclusión}

Después de transcurrido más de un siglo y medio la universidad y el cooperativismo parecen haberse encontrado de manera definitiva aunque todavía no completa ni suficientemente fecunda. Es como si todavía faltaran ajustes para asegurar una adecuada y eficiente compenetración entre ambos. La universidad todavía no se hecho cargo plenamente de la realidad cooperativa en sus diferentes aspectos y el cooperativismo aun no se ha abierto e integrado plenamente al ámbito académico. Queda pendiente una profundización de vínculos que permita resultados de mayor satisfacción recíproca. En ese camino, la complementación entre la investigación y la docencia, la presencia del cooperativismo en los programas de las diferentes carreras y el desarrollo de vínculos de intercambio y colaboración entre los centros universitarios especializados, constituyen medios que pueden contribuir al logro de esos resultados. 